\title{
Cox1 mutation abrogates need for Cox23 in cytochrome $c$ oxidase biogenesis
}

\author{
Richard Dela Cruz ${ }^{1,2}$, Mi-Young Jeong ${ }^{1}$ and Dennis R. Winge ${ }^{1, *}$ \\ ${ }^{1}$ University of Utah Health Sciences Center, Departments of Medicine and Biochemistry, Salt Lake City, Utah 84132, USA. \\ ${ }^{2}$ Present address: Oklahoma Medical Research Foundation, Oklahoma City, OK 73104, USA. \\ * Corresponding Author: \\ Dennis R. Winge, Tel: +1 801585 5103; Fax: +1 801585 3432; E-mail: dennis.winge@hsc.utah.edu
}

\begin{abstract}
Cox23 is a known conserved assembly factor for cytochrome $c$ oxidase, although its role in cytochrome $c$ oxidase $(\mathrm{CcO})$ biogenesis remains unresolved. To gain additional insights into its role, we isolated spontaneous

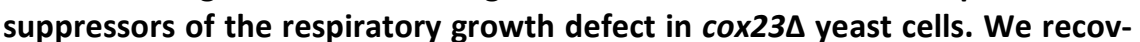
ered independent colonies that propagated on glycerol/lactate medium for cox $23 \Delta$ cells at $37^{\circ} \mathrm{C}$. We mapped these mutations to the mitochondrial genome and specifically to COX1 yielding an $\mathrm{I}^{101} \mathrm{~F}$ substitution. The $\mathrm{I}^{101} \mathrm{~F}$ Cox1 allele is a gain-of-function mutation enabling yeast to respire in the absence of Cox23. CcO subunit steady-state levels were restored with the $I^{101} \mathrm{~F}$ Cox1 suppressor mutation and oxygen consumption and $\mathrm{CcO}$ activity were likewise restored. Cells harboring the mitochondrial genome encoding $I^{101} F$ Cox 1 were used to delete genes for other $\mathrm{CcO}$ assembly factors to test the specificity of the Cox1 mutation as a suppressor of cox23 $\Delta$ cells. The Cox1 mutant allele fails to support respiratory growth in yeast lacking Cox17, Cox19, Coa1, Coa2, Cox14 or Shy1, demonstrating its specific suppressor activity for $\operatorname{cox} 23 \Delta$ cells.
\end{abstract}

doi: 10.15698/mic2016.07.511

Received originally: 17.03.2016;

in revised form: 25.05.2016,

Accepted 30.05.2016,

Published 30.06.2016.

Keywords: cytochrome oxidase, mitochondria, COX1, COX23.

\section{INTRODUCTION}

Cytochrome $c$ oxidase $(\mathrm{CcO})$ of the mitochondrial respiratory chain couples the reduction of molecular oxygen with proton translocation across the inner membrane (IM) to generate the membrane potential used to synthesize ATP. Mammalian $\mathrm{CcO}$ contains 14 subunits in which the 3 core subunits (Cox1-Cox3) are encoded by the mitochondrial genome $[1,2]$. This catalytic core is surrounded by nuclearencoded subunits, which confer enzyme stability and provide sites for the regulation of its activity $[3,4]$. The fully assembled holoenzyme is further organized into supercomplexes with other respiratory complexes [5-8]. Subunit 1 (Cox1) of CcO contains two heme $a$ and one copper ( $\mathrm{Cu}$ ) ion as cofactors [9]. One heme $a$ functions in electron transfer, whereas the second heme $a$ (heme $a_{3}$ ) has an open coordinate site where $\mathrm{O}_{2}$ binds in a reaction center that also contains the $\mathrm{Cu}_{\mathrm{B}}$ site. Cox2 contains a cysteinebridged, binuclear $\mathrm{Cu}$ site $\left(\mathrm{Cu}_{\mathrm{A}}\right)$ within a soluble globular domain that serves as the site of electron transfer from reduced cytochrome $c$.

The assembly of $\mathrm{CcO}$ requires a myriad of steps including the coordinated assembly of subunits translated on cytoplasmic and mitochondrial ribosomes and insertion of heme $a$ and copper cofactors. Studies with yeast mutants impaired in heme $a$ biosynthesis and $\mathrm{CcO}$ biogenesis have revealed that $\mathrm{CcO}$ assembly proceeds in a modular fashion with Cox1 maturation preceding independently of Cox 2 or Cox3 maturation [10-12]. Over 40 yeast accessory proteins have been found to be important for the assembly of $\mathrm{CCO}$ [13-15].

Hemylation and copper ion insertion are processes that occur within the intermembrane space (IMS) of mitochondria. The final step in heme $a$ formation is catalyzed by Cox15, which has its catalytic domain projecting into the IMS. The mechanism of insertion of heme $a$ into Cox 1 is not resolved, but this process is assisted by the IM protein Shy1 [16]. Copper ion metallation of Cox1 and Cox2 initiates within the IMS by the $\mathrm{Cu}(\mathrm{I})$ donor protein Cox17 [17]. Cox17-mediated $\mathrm{Cu}(\mathrm{I})$ donation involves two accessory factors Cox11 and Sco1 that function in the metallation of the $\mathrm{Cu}_{\mathrm{B}}$ site in Cox1 and $\mathrm{Cu}_{\mathrm{A}}$ site in Cox2, respectively [18, 19]. Both Cox11 and Sco1 are inner membrane (IM)associated proteins with $\mathrm{Cu}(\mathrm{I})$-binding globular domains protruding into the IMS. Cox17-mediated $\mathrm{Cu}(\mathrm{I})$ transfer to Sco1 is followed by the subsequent transfer to Cox2 in a reaction dependent on a key redox role of $\mathrm{Sco} 2$ in metazoans $[19,20]$. Likewise, Cox17-mediated $\mathrm{Cu}(\mathrm{I})$ transfer to 
A

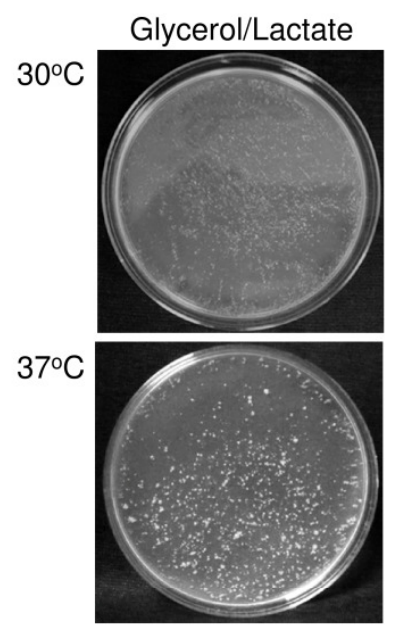

B

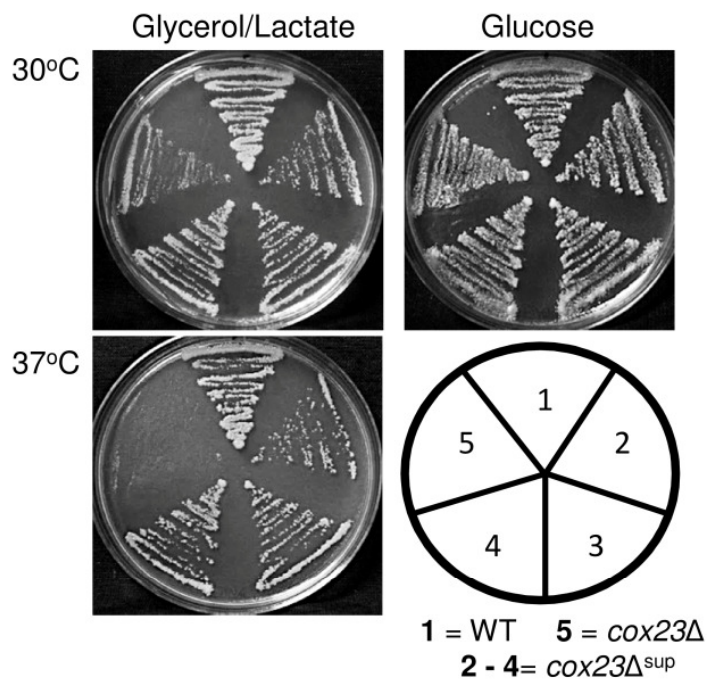

C

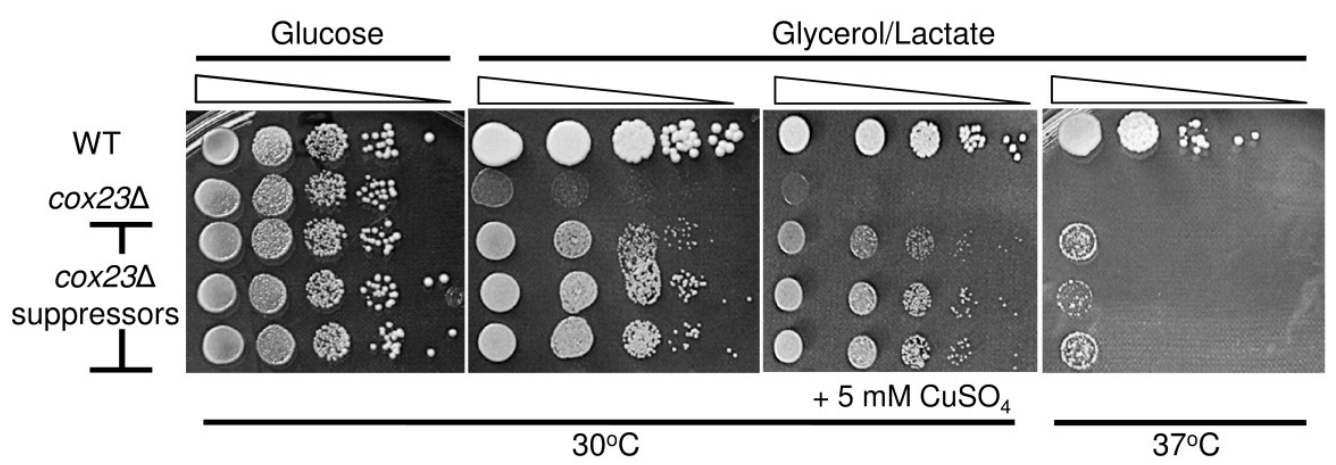

FIGURE 1: Growth properties of cox23 suppressors. (A) Diploid cox $23 \Delta$ yeast cells were plated at a density of $\sim 10^{7}$ cells/plate on YP glycerol/lactate (YPGL). The plates were photographed after 8 days of incubation at 30 and $37^{\circ} \mathrm{C}$. (B) BY4743, cox23A, and cox $23 \Delta$ suppressor cells were streaked on YPGL or YP-glucose (YPD) and incubated at the indicated temperatures. (C) Serial dilutions of BY4743, cox23A, and cox23 suppressors spotted on YPD or YPGL plates and incubated at $30^{\circ} \mathrm{C}$ for 2 and 5 days and at $37^{\circ} \mathrm{C}$ for 7 days, respectively (left most lane is $\mathrm{OD}_{600}=0.5$ ).

Cox11 is believed to occur prior to transfer to Cox1 forming the $\mathrm{Cu}_{\mathrm{B}}$ center $[18,21,22]$.

Cox17 is part of a family of IMS proteins including CcO assembly factors Cox19, Cox23, Pet191 and Cmc1 that all possess a conserved twin $\mathrm{Cx}_{9} \mathrm{C}$ structural motif $[17,23,24]$. Cox17 forms a helical hairpin conformation stabilized by two disulfide bonds of the twin $\mathrm{Cx}_{9} \mathrm{C}$ cysteines [25-27]. Cox 17 has 2 additional conserved $C y s$ residues upstream of the first $\mathrm{Cys}$ of the twin $\mathrm{C}_{9} \mathrm{C}$ motif, and these vicinal thiolates bind $\mathrm{Cu}(\mathrm{I})$ in a bis-coordinate complex [27]. A second of these twin $\mathrm{Cx}_{9} \mathrm{C}$ proteins Cox19 lacks the additional $\mathrm{Cu}(\mathrm{I})$ binding residues of Cox17 and was recently shown to interact with the inner membrane Cox 11 protein and mediates the redox regulation of Cox11 [28].

Cox23 also lacks the Cu-binding Cys residues and is not expected to bind $\mathrm{Cu}(\mathrm{I})$ in vivo. Yeast lacking $\mathrm{Cox} 23$ are $\mathrm{CcO}-$ deficient but residual levels of the enzyme persist [29]. The respiratory defect in cox $23 \Delta$ cells is partially suppressed by overexpression of Cox17 in cells only when cultured in 2 $\mathrm{mM} \mathrm{CuSO}_{4}[29]$. This observation led to speculation that
Cox23 functions in $\mathrm{Cu}$ delivery to $\mathrm{CcO}$ during its biogenesis. This prediction is consistent with a recent study in human cells. The abundance of the human Cox23 ortholog is attenuated in fibroblasts or myoblasts isolated from patients with mutations in $\mathrm{SCO} 1$ or $\mathrm{SCO} 2$ [30]. Furthermore, the abundance of Cox23 was attenuated in control fibroblasts treated with a Cu chelator to deplete cellular copper [30].

In the absence of any clear functional data on Cox23, we screened for spontaneous suppressors of the respiratory defect of cox23 $\Delta$ cells. In this report, we describe the isolation of a robust suppressor of the respiratory defect in $\operatorname{cox} 23 \Delta$ cells that mapped to the mitochondrial-encoded Cox1 subunit.

\section{RESULTS AND DISCUSSION}

Yeast lacking Cox23 exhibit a partial growth defect on glycerol/lactate growth medium. The respiratory growth defect is more pronounced in BY4741 cells relative to the W303 genetic background [29]. The growth impairment was sufficiently strong in BY4741 and BY4743 cells cultured at $37^{\circ} \mathrm{C}$ 
to permit a suppressor screen (Fig. 1C). We plated haploid and diploid cox $23 \Delta$ cells (BY4741 and BY4743, respectively) at a density of $\sim 10^{7}$ cells per plate on glycerol/lactate medium at both 30 and $37^{\circ} \mathrm{C}$. After 8 days a series of colonies appeared initially in the diploid null cells at $37^{\circ} \mathrm{C}$ relative to $30^{\circ} \mathrm{C}$ cultures (Fig. 1A). A series of respiratory competent colonies were collected and replated under respiratory conditions. Whereas the parent diploid $\operatorname{cox} 23 \Delta$ cells failed to propagate at $37^{\circ} \mathrm{C}$, the isolated colonies retained their ability to propagate at both 30 and $37^{\circ} \mathrm{C}$ temperatures (Fig. 1B). In serial dilution drop tests, the suppressors grew more robustly at $30^{\circ} \mathrm{C}$, but growth at $37^{\circ} \mathrm{C}$ although appar- ent but reduced relative to WT cells (Fig. 1C). The addition of exogenous copper sulfate did not enhance respiratory growth (Fig. 1C), and the addition of the copper (I) chelator bathocuproine sulfonate $(25 \mu \mathrm{M})$ impaired cox $23 \Delta$ cells and the cox23 suppressor strain (data not shown).

Mitochondria isolated from the suppressor colonies grown in galactose medium at $30^{\circ} \mathrm{C}$ were used for evaluation of $\mathrm{CcO}$ function. As can be seen in Fig. 2A, mitochondria isolated from the suppressors showed a stabilization of Cox1, Cox2, Cox5a and Cox13 subunit levels relative to the diploid null cells. Consistent with the respiratory growth shown in Fig. 1, the restoration of $\mathrm{CcO}$ subunits
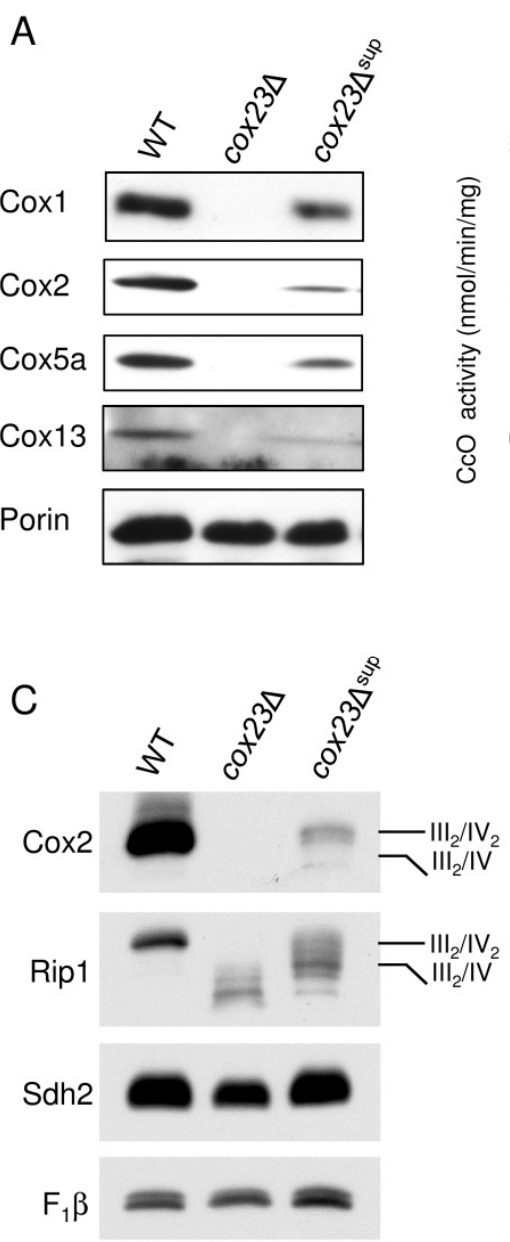

B

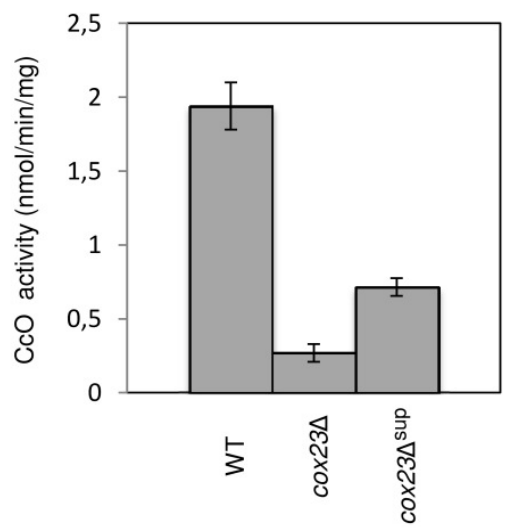

E

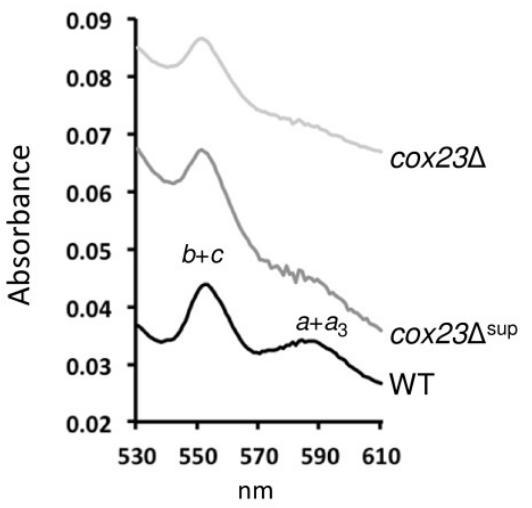

D

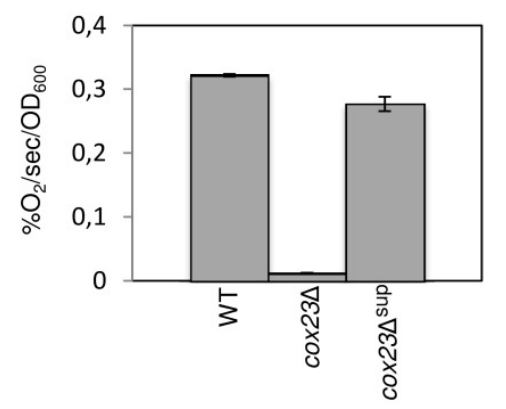

$\mathrm{F}$

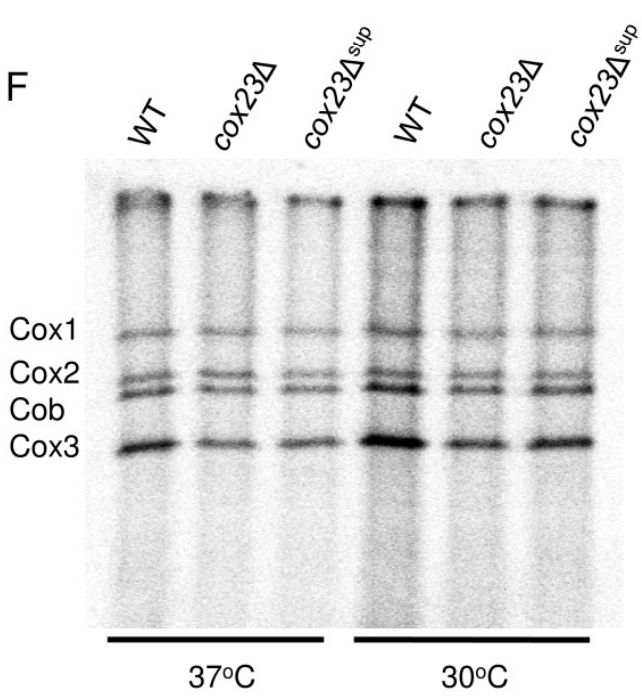

FIGURE 2: Functional characterization of cox23 $\Delta$ suppressor. (A) Steady-state concentration of representative Complex IV (CIV) subunits. Total mitochondrial protein $(20 \mu \mathrm{g})$ were separated on $12 \%$ SDS-PAGE, transferred to nitrocellulose and probed with CIV subunit specific antibodies and porin as loading control. (B) Mitochondria from WT, $\operatorname{cox} 23 \Delta$, and $\operatorname{cox} 23 \Delta$ suppressor cells grown in liquid YPGal were purified and assayed for $\mathrm{CcO}$ activity ( $\mathrm{nmol}$ cytochrome $c$ oxidized/min/mg protein). The data represents the average of four independent experiments (error bars indicate standard deviation). (C) Total mitochondrial protein $(30 \mu \mathrm{g})$ were solubilized in $1 \%$ digitonin, the mitochondrial protein complexes separated on a blue-native gel, then transferred to PVDF. The complexes were visualized using antibodies specific to subunits of the respiratory complexes. (D) WT, cox $23 \Delta$, and cox $23 \Delta$ suppressor cells were grown in liquid YP-Galactose (YPGal) at $30^{\circ} \mathrm{C}$ overnight and carbon-swapped to YPGL for 10 hours before oxygen consumption was measured. The data represents the average of three independent experiments (error bars indicate standard deviation). 1000 cells were plated in YPD-agar to confirm viability (data not shown). (E) Pyridine hemochromes analysis of mitochondrial hemes. Optical absorbance spectra were recorded of reduced minus oxidized cytochromes in the shown strains. (F) Mitochondrial proteins of wild-type (WT), $\operatorname{cox} 23 \Delta$, and $\operatorname{cox} 23 \Delta$ suppressor cells were pulse-labeled with $\left.{ }^{35} \mathrm{~S}\right]$-methionine for $7.5 \mathrm{~min}$ at $30^{\circ} \mathrm{C}$ and $37^{\circ} \mathrm{C}$. Total protein were extracted and separated on $15 \%$ polyacrylamide gel, then dried and exposed to $x$-ray film. 
was partial relative to WT cells. Consistent with the enhanced levels of $\mathrm{CcO}$ subunits, $\mathrm{CcO}$ enzymatic activity was elevated in the cox23A suppressors (Fig. 2B) and respiratory supercomplexes consisting of $b c_{1}$ and $\mathrm{CcO}$ were increased in abundance relative to the parent $\operatorname{cox} 23 \Delta$ null mutant (Fig. 2C). Cellular oxygen consumption was largely restored in the cox23 $\Delta$ suppressors (Fig. 2D) and heme $a / a_{3}$ levels were partially restored (Fig. 2E).

Mutant cells harboring the suppressor did not exhibit elevated levels of newly translated Cox1, Cox2 or Cox3 as seen in ${ }^{35} \mathrm{~S}$-methionine labeling in a mitochondrial translation assay. Mitochondrial translation was equivalent between cox23 mutant cells and the suppressor strain at both $30^{\circ} \mathrm{C}$ and $37^{\circ} \mathrm{C}$ (Fig. 2F).

Since the suppressors arose from the parent diploid BY4743 cox23 $\Delta$ strain, the suppressor mutation was likely either due to a dominant mutation or mitochondrial DNA mutation. To distinguish between these two scenarios, we conducted tetrad dissection of the diploid suppressors (Fig. $3 \mathrm{~A})$. Five tetrads shown exhibited the usual 2:2 segregation of LYS2 and MET15 markers in the diploid strain suggesting the tetrad dissection proceeded normally. However, all four spores in each suppressor were able to grow in glyc- erol/lactate medium. If a dominant nuclear mutation were responsible for the suppressor phenotype, then only two of the four spores would be expected to respire. Thus, we suspected the suppressor mutation was a mitochondrial DNA mutation. To test for this, we crossed a haploid $\operatorname{cox} 23 \Delta$ suppressor clone to a haploid $\operatorname{cox} 23 \Delta$ clone, which is derived from tetrad dissection of $\operatorname{cox} 23 \Delta$ suppressor, to generate diploids. The diploids were plated on either glucose or glycerol/lactate medium. As can be seen in Fig. 3B, approximately $50 \%$ of the diploids were respiratory competent in being able to propagate on glycerol/lactate medium. This is expected if the suppressor mutation was mitochondrial, since the diploids would retain either mitochondrial genome of the starting haploids.

The final proof of the mitochondrial origin of the $\operatorname{cox} 23 \Delta$ suppressor was in generating diploids once again

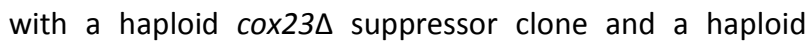
$\operatorname{cox} 23 \Delta$ parent null clone, but this time starting with one of these two strains as a rho variant. The rho ${ }^{\circ}$ variants were generated by propagating the strain on ethidium bromide $(\mathrm{EtBr})$ prior to conducting the cross. The resulting diploids were plated on glucose and glycerol/lactate. The only diploids capable of respiratory growth were those in which

A

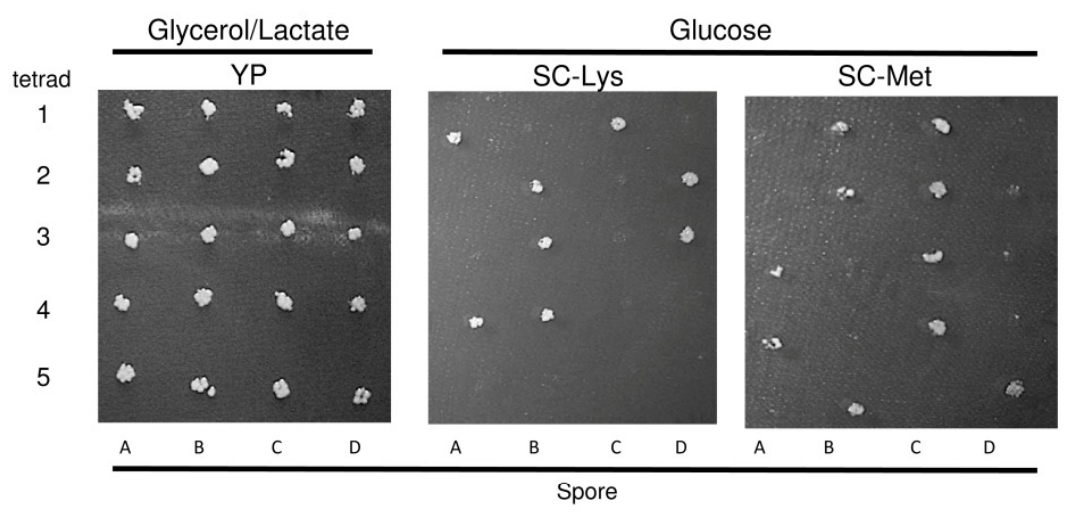

B

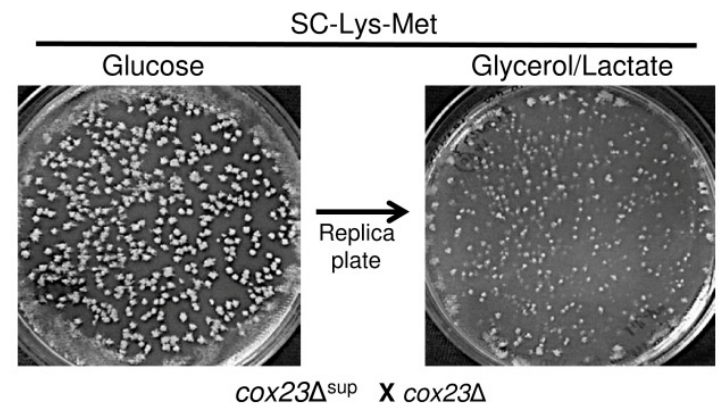

C

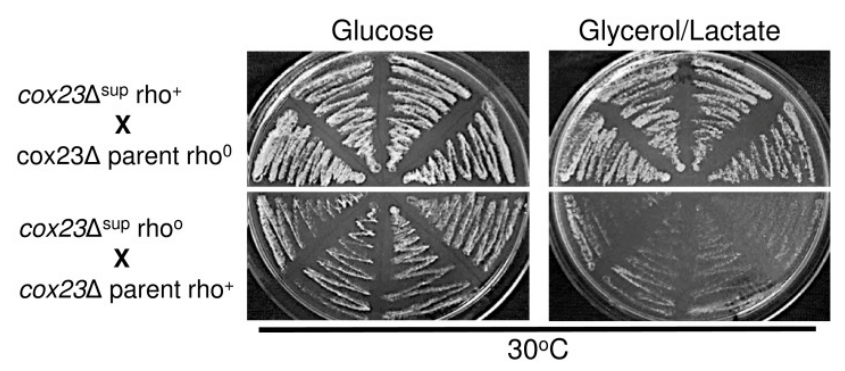

FIGURE 3: Confirmation of mtDNA origin of cox $\mathbf{2 3 \Delta}$ suppressor. (A) BY4743 cox23 $\Delta$ suppressors were grown in potassium acetate solution at room temperature to induce tetrad formation. After 4-5 days, tetrads were dissected and the spores were allowed to grow on YPD-Agar. The spores were replica plated into YPGL or SCD minus Lys or Met Agar plates to localize the suppressor DNA. (B) cox23 $\triangle$ suppressor spore was mated with cox $23 \Delta$ haploid of the opposite mating type. Approximately 1000 cells were allowed to grow in SCD minus Lys and Met Agar plate. The diploid colonies were then replica plated into SCGL minus Lys and Met plate to confirm the mitochondrial location of the suppressor. (C) $\operatorname{cox} 23 \Delta$ suppressor spore and $\operatorname{cox} 23 \Delta$ haploid cells were exposed to $\mathrm{EtBr}$ to induce rho ${ }^{\circ}$ status before mating with rho ${ }^{+} \operatorname{cox} 23 \Delta$ and $\operatorname{cox} 23 \Delta$ suppressor cells of the opposite mating type, respectively. Four colonies from each mating plate were streaked on YPD and then replica plated in YPGL to confirm the cox $23 \Delta$ mitochondrial suppressor. 
the mitochondrial DNA originated from the cox23 $\Delta$ suppressor (Fig. 3C). The diploids obtaining mitochondrial DNA from the parental cox23 $\Delta$ null failed to show growth on glycerol/lactate medium. This confirms that the mutation allowing respiratory growth of $\operatorname{cox} 23 \Delta$ cells resides within the mitochondrial genome.

To identify the mitochondrial mutation, DNA sequencing was carried out on COX1, COX2 and COX3 as the most likely candidates. No mutations were identified in COX2 or COX3. In contrast, an $\mathrm{A}>\mathrm{T}$ mutation was identified in codon 101 of COX1, which leads to an lle to Phe substitution (Fig. 4A). This is a conserved residue position in Cox1 with either lle or Met as the common residue. A Phe is found at this corresponding position in Schizosaccharomyces pombe and curiously this organism lacks Cox23 in its proteome. The position of this Met in the bovine Cox1 structure lies at the start of the third transmembrane helix and projects outward toward the interface of Cox1 and Cox3 near the matrix side of inner membrane (Fig. 4B).

To confirm that the $1 \mathrm{e}^{101}$ Phe substitution was responsible for conferring respiratory growth in $\operatorname{cox} 23 \Delta$ cells, we isolated haploid cells containing the mutant mitochondrial genome encoding Cox $1 \mathrm{I}^{101} \mathrm{~F}$ and subsequently deleted the COX23 locus (Fig. 4C). Cox1 $\mathrm{I}^{101} \mathrm{~F}$ containing yeast were competent to propagate on glycerol/lactate medium at $37^{\circ} \mathrm{C}$ regardless of the presence of Cox 23 . The respiratory growth of the cox $23 \Delta$ cells was similar to that of the starting cox23 3 suppressor cells.

We tested whether the Cox $1 \mathrm{I}^{101} \mathrm{~F}$ substitution was a gain-of-function mutation specific for only cox23 $\Delta$ cells. Cells with either a WT mitochondrial genome or the mutant COX1 genome were used to generate deletions in $\mathrm{CcO}$ biogenesis genes related to COX23. As mentioned, Cox23 is one of several soluble twin $\mathrm{Cx}_{9} \mathrm{C}$ proteins present within the IMS compartment, the other two being Cox17 and Cox19. Yeast harboring deletions in either COX17 or COX19 failed to propagate on glycerol/lactate medium regardless of whether Cox1 had the $\mathrm{I}^{101} \mathrm{~F}$ substitution or not (Fig. 5A). We also tested whether $\operatorname{Cox} 1 I^{101} \mathrm{~F}$ will facilitate respiratory growth in other $\mathrm{CCO}$ assembly mutants including SHY1, COA1 and COA2. Yeast lacking Shy1, Coa1 or Coa2 are partially impaired in $\mathrm{C} C \mathrm{O}$ biosynthesis and exhibit a respiratory
A

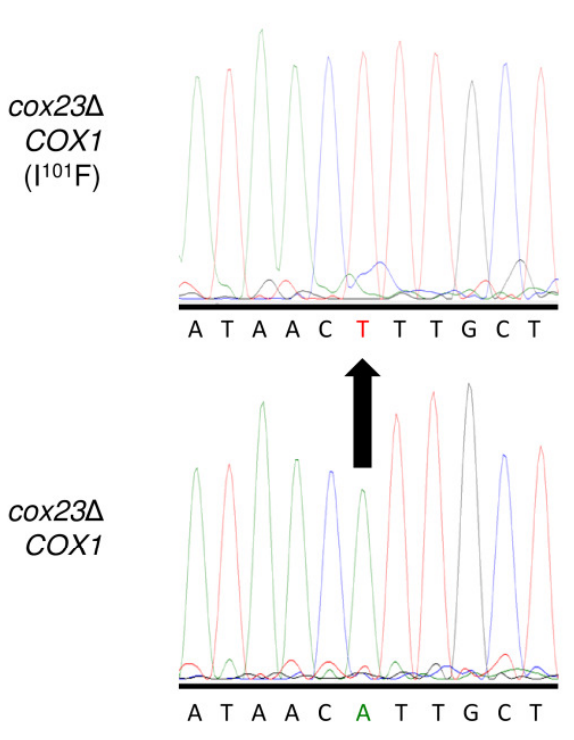

S. cerevisiae

S. pombe

Danio rerio

Bos indicus

Homo sapiens
B

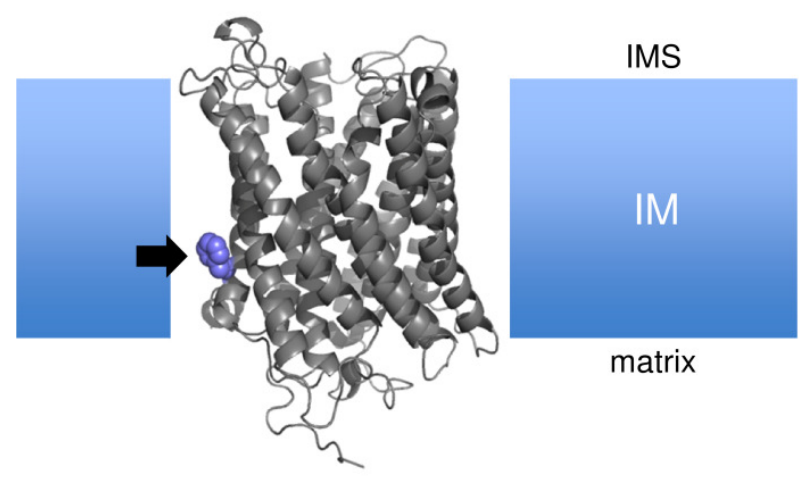

C

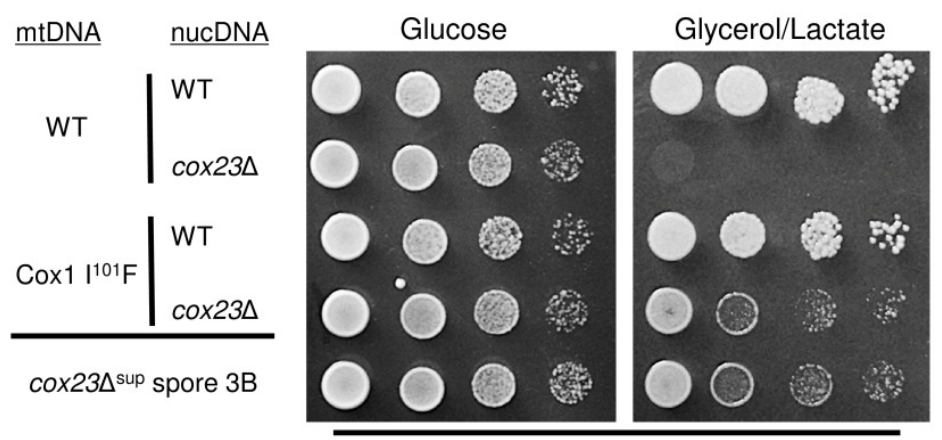

$37^{\circ} \mathrm{C}$

FIGURE 4: Identification of Cox1 $I^{101} \mathrm{~F}$ as the cox23 suppressor. (A) Cox1 ORF CDNA was isolated by RT-PCR. Sanger sequencing led to the identification of an $A \rightarrow T$ mutation causing an lle to Phe substitution in Cox1 at position 101 that curiously is wild-type in S. pombe (which lacks COX23 in its genome). (B) Probable location of the Cox1 mutation in the inner mitochondrial membrane based on sequence alignment to the Bos taurus crystal structure (1OCC.pdb). (C) Drop test on YPD and YPGL of Cox1 WT or $1^{101} \mathrm{~F}$-bearing haploid cells with or without introduced cox23 deletion (rows 1-4) compared to the cox23 spore known to contain $\operatorname{Cox} 11^{101} \mathrm{~F}$ (bottom, row 5). 
defect (Fig. 5B). The presence of the mutant COX1 allele failed to restore respiratory growth in any of these mutants, although growth was restored by vector-encoded SHY1, COA1 or COA2 in their respective mutants (Fig. 5B, bottom panel).
Respiratory growth of certain $\mathrm{CcO}$ assembly mutants, e.g. shy $1 \Delta$ and coa1 $1 \Delta$ cells, can be partially restored by overexpression of the Cox1 translational activator Mss51 [31]. We tested whether cox23 $\Delta$ cells are competent in respiratory growth upon overexpression of Mss51. Neither

A

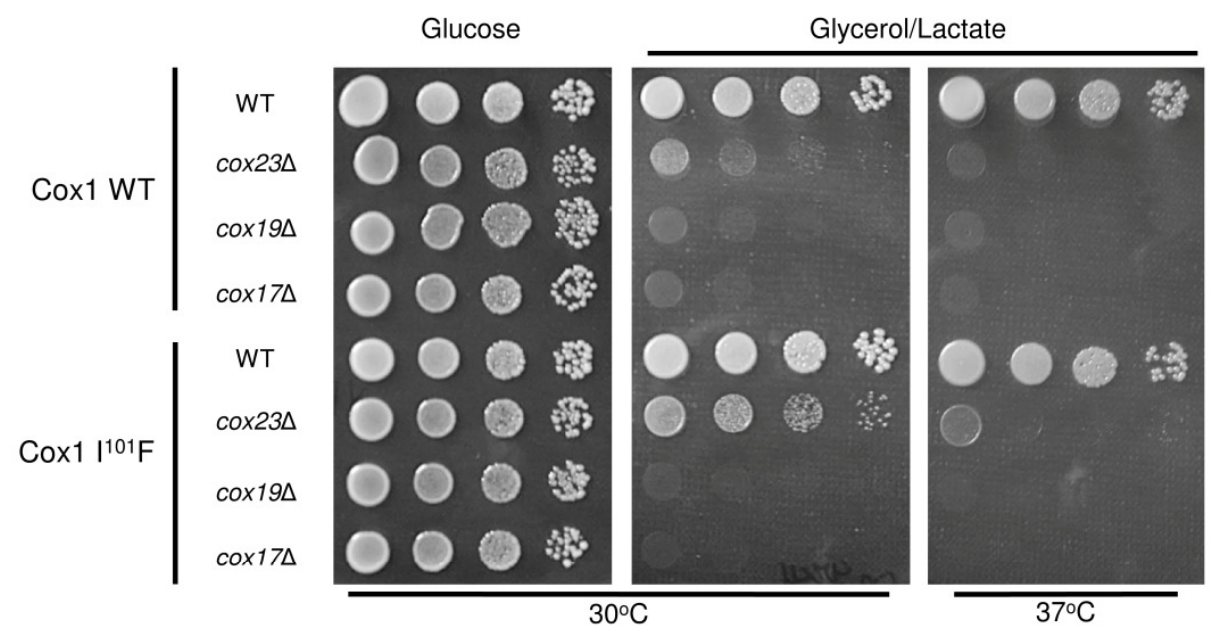

B

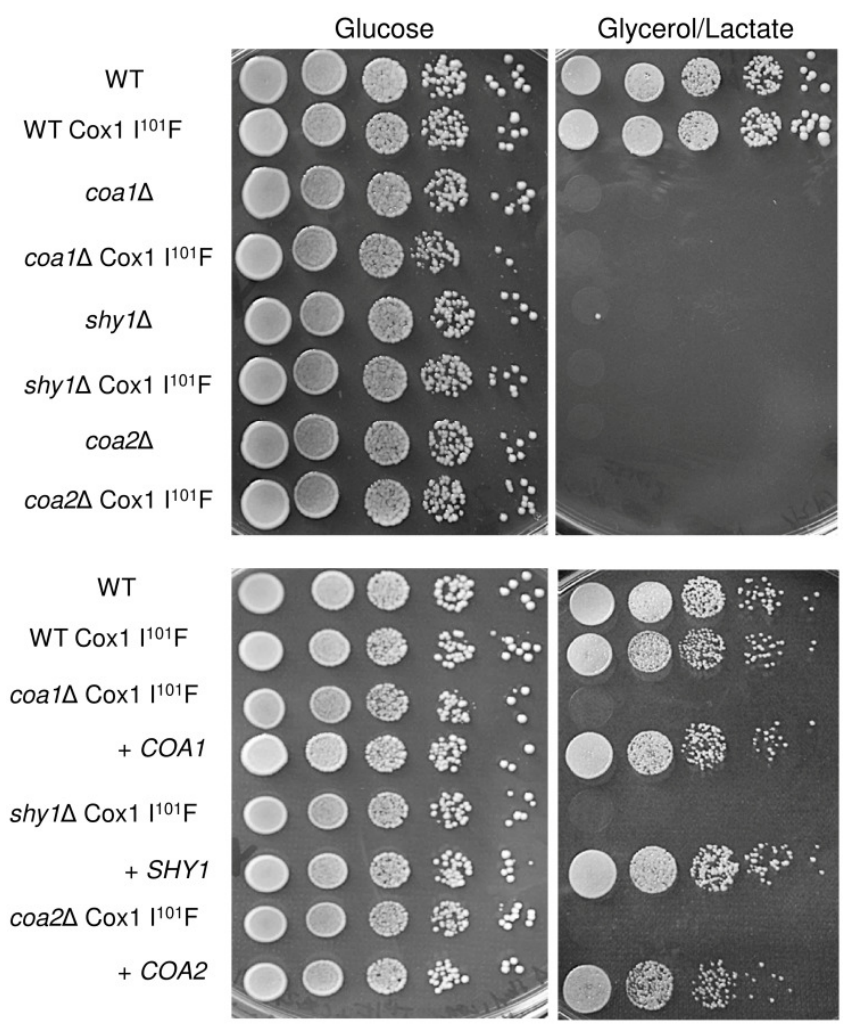

C

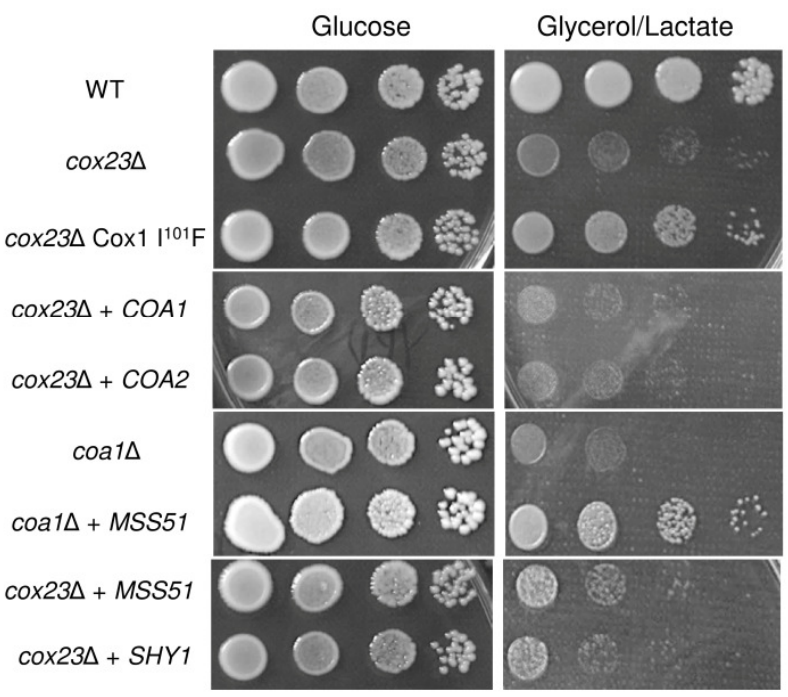

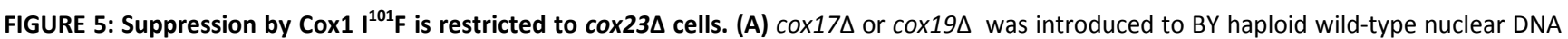
with or without Cox $11^{101} \mathrm{~F}$ mtDNA mutation and plated on YPD and YPGL plates for 3 and 7 days at $30^{\circ} \mathrm{C}$ respectively. (B) coa $1 \Delta$, coa $2 \Delta$ or shy $1 \Delta$ was introduced to BY haploid wild-type nuclear DNA with Cox $11^{101} \mathrm{~F}$ mtDNA mutation and plated on YPD and YPGL plates and incubated at $30^{\circ} \mathrm{C}$ for 3 and 7 days respectively. (C) cox23A cells were transformed with MSS51, SHY1, COA1 or COA2 overexpression plasmids and plated on YPD and YPGL plates and incubated for 3 and 7 days at $30^{\circ} \mathrm{C}$ respectively. 
high levels of Mss51, Shy1, Coa1 or Coa2 were able to mediate enhanced growth, unlike the suppressor effect seen with elevated levels of Mss51 in coa1 1 cells (Fig. 5C). Thus, Cox $1 I^{101} \mathrm{~F}$ is a specific suppressor of cox $23 \Delta$ cells.

Since $S$. pombe contains a Cox 1 with a Phe at the corresponding sequence position as the lle101 in yeast Cox1 and also lacks Cox14, we asked whether yeast containing the Cox $1 I^{101} \mathrm{~F}$ allele would be competent to respire in the absence of Cox14. To test this we introduced COX14 deletion in cox $23 \Delta$ suppressor strain and put plasmids-borne COX23 back to the strain. Yeast lacking Cox14 but containing mitochondria with the Cox $1 \mathrm{I}^{101} \mathrm{~F}$ allele were unable to propagate on glycerol/lactate rich medium (Fig. 6A). Overexpression of Cox23 from either a low or high copy vector failed to restore respiratory growth of cox $14 \Delta$ cells containing the Cox1 Phe101 mitochondrial protein.

Since we recovered the cox $23 \Delta$ suppressor under respiratory condition at $37^{\circ} \mathrm{C}$ in which more reactive oxygen species are generated, we tested how the suppressor behave under the reactive oxidative stress condition. Yeast harboring the $\operatorname{Cox} 1{ }^{101} \mathrm{~F}$ allele did not exhibit any enhanced sensitivity or resistance to reactive oxygen stress induced by culturing the cells in increasing levels of paraquat (Fig. $6 \mathrm{~B}$ ), whereas the presence of $\operatorname{Cox} 1 \mathrm{I}^{101} \mathrm{~F}$ in cox $23 \Delta$ cells led to a slight resistance toward paraquat. This contrasts with the known paraquat sensitivity of $s d h 6 \Delta$ cells [32].

In summary, we recovered independent colonies that propagated on glycerol/lactate medium for cox $23 \Delta$ cells. We mapped these mutations to the mitochondrial genome and specifically to COX1 yielding an $1^{101} \mathrm{~F}$ substitution. The $1^{101} \mathrm{~F}$ Cox 1 allele is a gain-of-function mutation enabling yeast to respire in the absence of Cox23. CcO steady-state levels were restored with the $1^{101} \mathrm{~F}$ Cox 1 suppressor muta- tion and oxygen consumption and $\mathrm{CcO}$ activity were likewise restored. The allele fails to support respiratory growth in yeast lacking Cox17, Cox19 Coa1, Coa2, Cox14 or Shy1, demonstrating its specific suppressor activity for cox $23 \Delta$ cells.

Most species have an Ile, Leu or Met at the corresponding lle101 sequence position. In contrast, S. pombe has a Phe at this position in Cox1. The gain-of-function $I^{101} \mathrm{~F}$ Cox 1 allele in the $S$. cerevisiae cox $23 \Delta$ deletion mutant may provide an explanation for the lack of Cox23 in S. pombe. Ile101 is situated at the start of TM3 in Cox1 near the matrix side of the IM. This residue in the bovine $\mathrm{CcO}$ structure projects outward packing against the first TM helix in Cox3 [33] (Fig. 4B).

Despite the present studies, the function of Cox23 in $\mathrm{CcO}$ biogenesis remains unresolved. This work reveals a potential role in Cox1 maturation. Recently, the Cox23 homolog Cox19 was shown to shield the $\mathrm{Cu}_{\mathrm{B}}$ metallochaperone Cox11 from oxidation on a membrane proximal cysteinyl residue [28]. If Cox23 has a related function, the redox state of the remaining two $\mathrm{Cu}(\mathrm{I})$-binding cysteinyl residues in Cox11 may be dependent on Cox23. Cox19 and Cox23 may have non-redundant roles with Cox11 in forming the Cox1 $\mathrm{Cu}_{\mathrm{B}}$ site in many species, but the $1^{101} \mathrm{~F}$ Cox 1 allele may permit Cox19 to perform both functions in $S$. pombe and the present $S$. cerevisiae mutant. Alternatively, Cox23 may have a novel role in the hemylation of Cox1 in an unresolved heme $a$ transfer step. Further research is needed to resolve these scenarios.
A

\section{WT}

$\operatorname{cox} 14 \Delta$

$\operatorname{cox} 14 \Delta \operatorname{Cox} 1 \mathrm{I}^{101} \mathrm{~F}$
Glucose

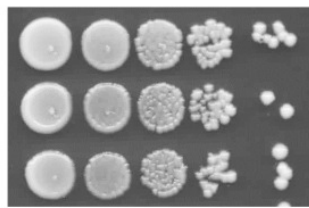

Glycerol/Lactate

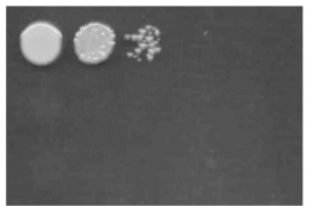

B

Glycerol/Lactate

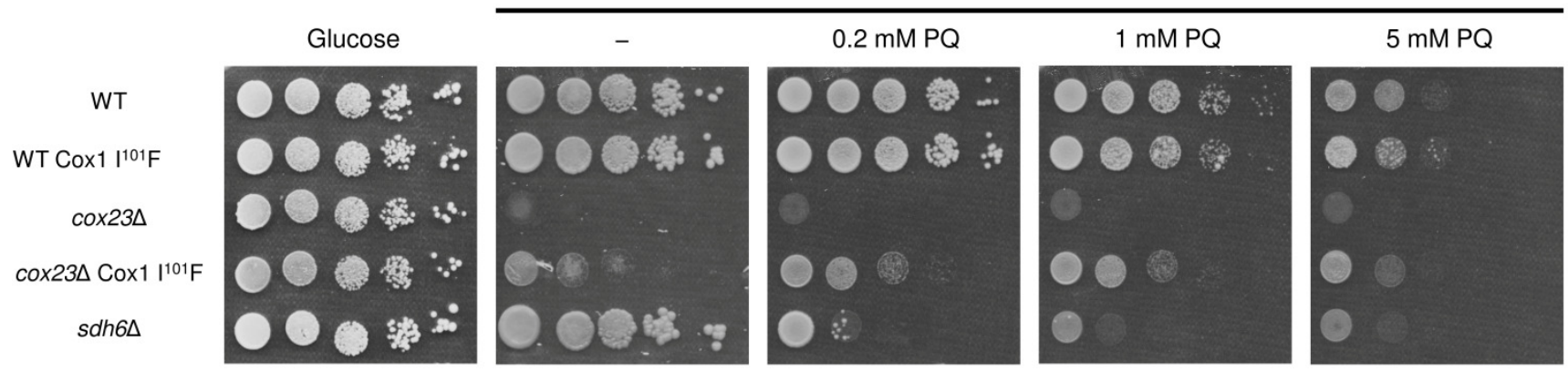

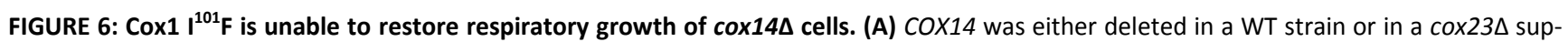
pressor strain. High-copy or low-copy plasmids containing $\operatorname{COX} 23$ were transformed to $\operatorname{cox} 14 \Delta \operatorname{cox} 23 \Delta$ deletion strain to make the strain a cox14 $\triangle$ containing COX1 suppressor mutation. The resulting cells were tested for respiratory growth. (B) cox $23 \Delta$ mutant cells with and without the Cox $1 \mathrm{I}^{101} \mathrm{~F}$ allele were plated on glycerol/lactate medium containing increasing concentrations of paraquat $(0-5 \mathrm{mM})$ at $30^{\circ} \mathrm{C}$. 


\section{MATERIALS AND METHODS \\ Yeast Strains and Vectors}

The Saccharomyces cerevisiae yeast strains used in this study were from a yeast knockout collection (Invitrogen). The COA1, COA2, SHY1, and MSS51 ORFs were cloned into plasmid pRS413 and pRS416 under control of the MET25 promoter and CYC1 terminator. Yeast strains were transformed using lithium acetate. Yeast cells were cultured either in rich medium (YP) or synthetic complete (SC) medium lacking the appropriate nutrients for plasmid selection. Final concentration of carbon sources used (glucose, galactose, glycerol, lactate) in liquid media and agar plates is $2 \%$ except for raffinose $(0.2 \%)$. Spores from diploid transformants were recovered after sporulation in $0.3 \%$ potassium acetate for 5 days at room temperature (RT). Rho ${ }^{\circ}$ cells were obtained after overnight incubation of yeast cells in YP-Glucose (YPD) with ethidium bromide (EtBr) at RT.

\section{Mitochondrial Purification}

Intact mitochondria were isolated from yeast as described previously [34]. Total mitochondrial protein concentration was determined using Coomassie Plus Protein Assay Reagent (ThermoScientific).

\section{Blue Native PAGE}

Blue Native PAGE (BN-PAGE) was performed as previously described [35]. Briefly, 20 to $30 \mu \mathrm{g}$ isolated mitochondria was solubilized in sample buffer ( $1 \%$ digitonin, $0.5 \mathrm{M}$ 6aminocaproic acid, $\mathrm{pH} 7.0$ ), incubated in ice for $20 \mathrm{~min}$ and then centrifuged $\left(20,000 \times g\right.$ for $10 \mathrm{~min}$ at $\left.4^{\circ} \mathrm{C}\right)$. Supernatants were mixed with $0.5 \mu \mathrm{l} 5 \%$ Coomassie brilliant blue G250 and loaded on a NativePAGE Novex ${ }^{\mathrm{TM}}$ 3-12\% gradient polyacrylamide gel (Invitrogen) alongside a high-mass protein marker (GE Healthcare).

\section{Immunoblotting}

BN-PAGE mass-resolved complexes were detected after transfer to a polyvinylidene difluoride (PVDF) membrane. Alterna- tively, mitochondrial proteins were detected after separation of 10 to $30 \mu \mathrm{g}$ solubilized and reduced mitochondria on $12 \%$ SDS-PAGE gel and transfer to nitrocellulose. Proteins were visualized using Supersignal (ThermoScientific) to detect horseradish peroxidase-conjugated secondary antibodies. Primary antibodies used were either purchased or generous gifts: anti-Cox1 and anti-Cox2 (Mitoscience), anti-Porin (Molecular Probes), Anti-Sdh2 (21st Century Biochemicals), anti-F1 ATPase (Dr. A. Tzagoloff), anti-Cyt1 and anti-Cox5a (Dr. B. Meunier), and anti-Cox13 (Dr. P. Rehling).

\section{Miscellaneous Assays}

$\mathrm{CcO}$ activity in isolated mitochondria were determined spectrophotometrically by supplying reduced cytochrome $c$ and following the initial rate of cytochrome $c$ oxidation at $550 \mathrm{~nm}$ using an Agilent 8453 spectrophotometer. Reduced cytochrome $c$ was prepared by adding equimolar amount of sodium hydrosulfite (Aldrich) to horse heart cytochrome $c$ (Sigma) and desalting using a PD-10 gravity flow colum (GE Healthcare). The rate of oxygen consumption of cells grown in YP-Galactose (YPGal) media then carbon-swapped to YPGlycerol/Lactate (YPGL) was determined from the linear response on a 5300A biological oxygen monitor (Yellow Springs Instruments Co.). Optical absorption spectroscopy was used to monitor mitochondrial heme pools. Two mg of purified mitochondria was suspended in $250 \mu \mathrm{l}$ of distilled water. Same volume of a stock solution ( $200 \mathrm{mM} \mathrm{NaOH}, 40 \%$ pyridine) and $1.5 \mu \mathrm{l}$ of $0.1 \mathrm{M} \mathrm{K}_{3} \mathrm{Fe}(\mathrm{CN})_{6}$ were added to the mitochondrial suspension. Each spectrum represents the calculated difference spectrum of the reduced (dithionite) minus oxidized (ferricyanide) cytochromes and was recorded by an Agilent 8453 spectrophotometer. Absorption maxima at 550 and $558 \mathrm{~nm}$ correspond to cytochromes $b / c$ and $a / a_{3}$, respectively.

For in vivo mitochondrial translation assay, cells were grown overnight in YPGal media to an $\mathrm{OD}_{600}$ of $\left.1 .{ }^{35} \mathrm{~S}\right]-$ methionine labeling and sample preparation for $15 \%$ SDSPAGE was performed as previously described [36]. Gels were dried and radiolabelled mitochondrial proteins were visualized

TABLE 1. Genotype and sources of yeast strains.

\begin{tabular}{|c|c|c|}
\hline Strain & Genotype & Source \\
\hline BY4743 & 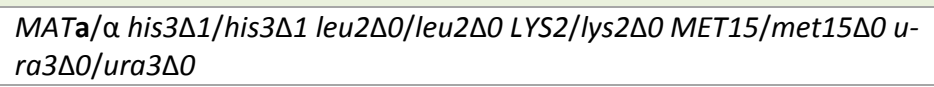 & Invitrogen \\
\hline BY4743 $\operatorname{cox} 23 \Delta$ & $\begin{array}{l}M A T a / \alpha \text { his } 3 \Delta 1 / \text { his } 3 \Delta 1 \text { leu } 2 \Delta 0 / \text { leu } 2 \Delta O \text { LYS2/lys } 2 \Delta O M E T 15 / \text { met } 15 \Delta O \text { u- } \\
\text { ra3 } \Delta 0 / \text { ura3 } \Delta 0 \Delta \operatorname{cox} 23:: k a n M X 4\end{array}$ & Invitrogen \\
\hline BY4741 & MATa his $3 \Delta 1$ leu $2 \Delta 0$ met $15 \Delta 0$ ura $3 \Delta 0$ & Invitrogen \\
\hline BY4741 $\operatorname{cox} 23 \Delta$ & MATa his $3 \Delta 1$ leu $2 \Delta 0$ met $15 \Delta 0$ ura $3 \Delta 0 \Delta \operatorname{cox} 23:: k a n M X 4$ & Invitrogen \\
\hline BY4741 cox19A & MATa his $3 \Delta 1$ leu $2 \Delta 0$ met $15 \Delta 0$ ura $30 \Delta \operatorname{cox} 19:: k a n M X 4$ & Invitrogen \\
\hline BY4741 $\operatorname{cox} 17 \Delta$ & MATa his $3 \Delta 1$ leu $2 \Delta 0$ met $15 \Delta 0$ ura $3 \Delta 0 \Delta \operatorname{cox} 17:: k a n M X 4$ & Invitrogen \\
\hline BY4741 $\operatorname{coa} 1 \Delta$ & MATa his $3 \Delta 1$ leu $2 \Delta 0$ met $15 \Delta 0$ ura $3 \Delta 0 \Delta \operatorname{coa} 1:: k a n M X 4$ & Invitrogen \\
\hline BY4741 coa2 $\Delta$ & MATa his $3 \Delta 1$ leu $2 \Delta 0$ met $15 \Delta 0$ ura3 $\Delta 0 \Delta \operatorname{coa} 2:: k a n M X 4$ & Invitrogen \\
\hline BY4741 shy $1 \Delta$ & MATa his $3 \Delta 1$ leu $2 \Delta 0$ met $15 \Delta 0$ ura $3 \Delta 0 \Delta$ shy $1:: k a n M X 4$ & Invitrogen \\
\hline
\end{tabular}


by overnight film autoradiography. Growth tests to determine the respiratory competency of yeast strains were performed on agar plates containing $2 \%$ glucose or $2 \%$ glycerol-2\% lactate. Yeast cells were grown overnight in YPD medium and adjusted to an optical density at $600 \mathrm{~nm}$ of 0.5 . Serial dilutions were spotted onto plates and incubated at $30^{\circ} \mathrm{C}$ for 2 days (glucose plates) or 4 to 8 days (glycerol-lactate plates). Bathocuproine sulfonate (BCS) and bathophenanthroline sulfonate (BPS) were purchased from Sigma.

\section{ACKNOWLEDGMENTS}

This work was supported by grant ES03817 from the National Institutes of Environmental Health Sciences NIH to D.R.W. R.D.C. was supported by training grant T32 DK007115 from the National Institutes of Health.

\section{SUPPLEMENTAL MATERIAL}

All supplemental data for this article are available online at www.microbialcell.com.

\section{REFERENCES}

1. Yoshikawa S, Shinzawa-Itoh K and Tsukihara T (2000) X-ray structure and the reaction mechanism of bovine heart cytochrome $c$ oxidase. J Inorg Biochem 82:1-7.

2. Balsa $E$, Marco R, Perales-Clemente $E$, Szklarczyk R, Calvo $E$, Landazuri MO and Enriquez JA (2012) NDUFA4 is a subunit of complex IV of the mammalian electron transport chain. Cell Metab 16:378-86.

3. Fontanesi F, Soto IC and Barrientos A (2008) Cytochrome C oxidase biogenesis: new levels of regulation. IUBMB Life 60:557-68.

4. Fontanesi F, Soto IC, Horn D and Barrientos A (2006) Assembly of mitochondrial cytochrome c-oxidase, a complicated and highly regulated cellular process. Am J Physiol Cell Physiol 291:C1129-47.

5. Cruciat $\mathrm{CM}$, Brunner S, Baumann F, Neupert $\mathrm{W}$ and Stuart RA (2000) The cytochrome bc1 and cytochrome c oxidase complexes associate to form a single supracomplex in yeast mitochondria. J Biol Chem 275:18093-18098.

6. Schagger $H$ and Pfeiffer $K$ (2000) Supercomplexes in the respiratory chains of yeast and mammalian mitochondria. EMBO J 19:1777-83.

7. Schagger H (2001) Respiratory chain supercomplexes. IUBMB Life 52:119-28.

8. Eubel H, Heinemeyer J, Sunderhaus S and Braun HP (2004) Respiratory chain supercomplexes in plant mitochondria. Plant Physiol Biochem 42:937-42.

9. Tsukihara T, Aoyama H, Yamashita E, Tomizaki T, Yamaguchi $H$, Shinzawa-Itoh K, Hakashima R, Yaono R and Yoshikawa S (1995) Structures of metal sites of oxidized bovine heart cytochrome c oxidase at 2.8A. Science 269:1069-1074.

10. McStay GP, Su CH, Thomas SM, Xu JT and Tzagoloff A (2013) Characterization of assembly intermediates containing subunit 1 of yeast cytochrome oxidase. J Biol Chem 288, 26546-56.

11. McStay GP, Su CH and Tzagoloff A (2012) Modular assembly of yeast cytochrome oxidase. Mol Biol Cell 24:440-452.

12. Su CH, McStay GP and Tzagoloff A (2014) The Cox3p assembly module of yeast cytochrome oxidase. Mol Biol Cell 25:965-76.

13. Tzagoloff $A$ and Dieckmann CL (1990) PET Genes of Saccharomyces cerevisiae. Microbiological Rev. 54:211-225.

\section{CONFLICT OF INTEREST}

None of the authors have a conflict of interest with this reported study.

\section{COPYRIGHT}

(C) 2016 Dela Cruz et al. This is an open-access article released under the terms of the Creative Commons Attribution (CC BY) license, which allows the unrestricted use, distribution, and reproduction in any medium, provided the original author and source are acknowledged.

Please cite this article as: Richard Dela Cruz, Mi-Young Jeong and Dennis R. Winge (2016). Cox1 mutation abrogates need for Cox23 in cytochrome $c$ oxidase biogenesis. Microbial Cell 3(7): 275-284. doi: 10.15698/mic2016.07.511

14. Barrientos A, Barros MH, Valnot I, Rotig A, Rustin P and Tzagoloff A (2002) Cytochrome oxidase in health and disease. Gene 286:53-63.

15. Soto IC, Fontanesi F, Liu J and Barrientos A (2012) Biogenesis and assembly of eukaryotic cytochrome c oxidase catalytic core. Biochim Biophys Acta 1817:883-97.

16. Khalimonchuk O, Bestwick $M$, Meunier B, Watts TC and Winge DR (2010) Formation of the redox cofactor centers during Cox1 maturation in yeast cytochrome oxidase. Mol Cell Biol 30:1004-17.

17. Glerum DM, Shtanko A and Tzagoloff A (1996) Characterization of COX17, a Yeast Gene Involved in Copper Metabolism and Assembly of Cytochrome Oxidase. J Biol Chem 271:14504-14509.

18. Horng YC, Cobine PA, Maxfield AB, Carr HS and Winge DR (2004) Specific copper transfer from the Cox17 metallochaperone to both Sco1 and Cox11 in the assembly of yeast cytochrome $c$ oxidase. J Biol Chem 279:35334-40.

19. Banci L, Bertini I, Ciofi-Baffoni S, Hadjiloi T, Martinelli M and Palumaa P (2008) Mitochondrial copper(I) transfer from Cox17 to Sco1 is coupled to electron transfer. Proc Natl Acad Sci U S A 105:68036808.

20. Leary SC, Sasarman F, Nishimura T and Shoubridge EA (2009) Human SCO2 is required for the synthesis of $\mathrm{CO}$ II and as a thioldisulphide oxidoreductase for SCO1. Hum Mol Genet 18:2230-40.

21. Carr HS, George GN and Winge DR (2002) Yeast Cox11, a protein essential for cytochrome c oxidase assembly, is a $\mathrm{Cu}(\mathrm{I})$ binding protein. J Biol Chem 277:31237-31242.

22. Banci L, Bertini I, Cantini F, Ciofi-Baffoni S, Gonnelli L and Mangani $S$ (2004) Solution structure of Cox11: A novel type of beta immunoglobulin-like fold involved in $\mathrm{CuB}$ site formation of cytochrome c oxidase. J Biol Chem 279:34,833-34,839.

23. Khalimonchuk $O$ and Winge DR (2007) Function and redox state of mitochondrial localized cysteine-rich proteins important in the assembly of cytochrome c oxidase. Biochim Biophys Acta 1783:618628.

24. Longen S, Bien M, Bihlmaier K, Kloeppel C, Kauff F, Hammermeister M, Westermann B, Herrmann JM and Riemer J (2009) Systematic analysis of the twin $\mathrm{cx}(9) \mathrm{c}$ protein family. J Mol Biol 393:356-68. 
25. Abajian C, Yatsunyk LA, Ramirez BE and Rosenzweig AC (2004) Yeast Cox17 Solution Structure and Copper(I) Binding. J Biol Chem 279:53584-53592.

26. Arnesano F, Balatri E, Banci L, Bertini I and Winge DR (2005) Folding studies of Cox17 reveal an important interplay of cysteine oxidase and copper binding. Structure 13:713-722.

27. Banci L, Bertini I, Ciofi-Baffoni S, Janicka A, Martinelli M, Kozlowski $\mathrm{H}$ and Palumaa $\mathrm{P}$ (2008) A structural-dynamical characterization of human Cox17. J Biol Chem 283:7912-7920.

28. Bode $M$, Woellhaf $M W$, Bohnert $M$, van der Laan $M$, Sommer $F$, Jung $M$, Zimmermann R, Schroda M and Herrmann JM (2015) Redoxregulated dynamic interplay between Cox19 and the copper-binding protein Cox11 in the intermembrane space of mitochondria facilitates biogenesis of cytochrome c oxidase. Mol Biol Cell 26:2385-401.

29. Barros MH, Johnson A and Tzagoloff A (2004) Cox23, a homologue of COX17, is required for cytochrome oxidase assembly. J. Biol. Chem. 279:31943-31947.

30. Leary SC, Cobine PA, Nishimura T, Verdijk RM, de Krijger R, de Coo R, Tarnopolsky MA, Winge DR and Shoubridge EA (2013) COX19 mediates the transduction of a mitochondrial redox signal from SCO1 that regulates ATP7A-mediated cellular copper efflux. Mol Biol Cell 24:683-91.
31. Pierrel F, Bestwick $M$, Cobine $P$, Khalimonchuk $O$, Cricco J and Winge D (2007) Coa1 links the Mss51 post-translational function to Cox1 cofactor insertion in cytochrome c oxidase assembly. EMBO J 26:4335-4346.

32. Na U, Yu W, Cox J, Bricker DK, Brockmann K, Rutter J, Thummel CS and Winge DR (2014) The LYR factors SDHAF1 and SDHAF3 mediate maturation of the iron-sulfur subunit of succinate dehydrogenase. Cell Metab 20:253-66.

33. Tsukihara $\mathrm{T}$, Aoyama $\mathrm{H}$, Yamashita E, Tomizaki T, Yamaguichi $\mathrm{H}$, Shinzawa-Itoh K, Nakashima R, Yaono R and Yoshikawa S (1996) The whole structure of the 13-subunit oxidized cytochrome c oxidase at 2.8 A. Science 272:1136-1144.

34. Diekert K, De Kroon Al, Kispal G and Lill R (2001) Isolation and subfractionation of mitochondria from the yeast Saccharomyces cerevisiae. Meth Cell Biol 65:37-51.

35. Wittig I, Braun HP and Schagger H (2006) Blue native PAGE. Nat Protoc 1:418-28.

36. Barrientos A, Korr D and Tzagoloff A (2002) Shy1p is necessary for full expression of mitochondrial COX1 in the yeast model of Leigh's syndrome. EMBO J 21:43-52. 